\title{
O LÚDICO NA POESIA PARA CRIANÇAS DE JOSÉ PAULO PAES E DE MANOEL DE BARROS
}

Nismária Alves David (UEG)

Resumo: A partir da relação existente entre poesia e jogo, apontada por Huizinga (1971), este trabalho estuda os livros Poemas para brincar, de José Paulo Paes, e Poeminha em língua de brincar, de Manoel de Barros, com o objetivo de analisar os expedientes linguísticos mobilizados para a composição do caráter lúdico nas referidas obras e, assim, contribuir para o aprofundamento dos conhecimentos a respeito da lírica contemporânea voltada às crianças, em especial, produzida por esses representativos escritores da literatura brasileira.

Palavras-chave: poesia, jogo, criança, leitor.

Abstract: From the relationship between poetry and playful, appointed by Huizinga (1971), this work studies the books Poemas para brincar, by José Paulo Paes, and Poeminha em língua de brincar, by Manoel de Barros, in order to analyze the linguistic expedients mobilized for character the playful in these works. Thus it contributes to increase knowledge about the contemporary lyric directed to children, in particular, produced by these representative writers of Brazilian literature.

Keywords: poetry, playful, child, reader.

\section{INTRODUÇÃO}

Este trabalho estuda os livros Poemas para brincar, de José Paulo Paes, e Poeminha em língua de brincar, de Manoel de Barros, publicados em 1990 e em 2007, respectivamente. O motivo da escolha desse corpus se deve ao fato de que, embora haja distância temporal entre as publicações, são dois exemplos de criação poética em que se revela um sujeito-lírico cuja visão de mundo se aproxima da visão de 
mundo da criança e os versos são concebidos como um jogo com as palavras. Conforme já atestam os títulos das referidas obras, na poesia para crianças de Paes e de Barros, conjugam-se os atos de escrever e ler com o ato de brincar, isto é, entre a metalinguagem e o lúdico.

Na Literatura Brasileira para crianças, conforme Zilberman (2005), a compreensão de que o lúdico está intimamente relacionado à linguagem poética propiciou a valorização do jogo à expansão da poesia para crianças, principalmente, a partir da década de 1980. Por essa razão, os poemas contemporâneos destinados ao público-leitor infantil tocam o universo da criança sempre destacando a brincadeira, o tratamento lúdico da linguagem, substituindo a orientação cívica e os traços parnasianos herdados de Olavo Bilac e de Francisca Júlia (ZILBERMAN, 2005). De fato, há a necessidade de a poesia para as crianças ser valorizada como arte literária, "devendo instaurar-se por um discurso autônomo, antes de ensinar os bons costumes" (ZILBERMAN \& MAGALHÃES, 1987, p.40). No dizer de Perrotti (1986), a literatura para crianças torna-se útil, deixando de ser utilitária.

A relevância deste trabalho consiste na divulgação das obras poéticas de Paes e de Barros voltadas ao público-leitor infantil, visto que a maioria dos estudos direcionados a ambos 
os poetas contempla as obras endereçadas ao público-leitor adulto. Conforme assinala Turchi:

[...] mais do que nunca, é tarefa da crítica da literatura infantil e juvenil: a avaliação - analisar a literatura contemporânea, o crítico tem responsabilidade com a arte de sua própria época; a seleção mostrar o que ler ou reler e de que modo; a formação - estabelecer conexões, abrindo para estudos culturais mais amplos, envolvendo todo o processo de leitura. (TURCHI, 2002, p.30)

Diante disso, aqui, realiza-se o exercício de crítica literária, que contribui para o aprofundamento dos conhecimentos a respeito da lírica contemporânea brasileira voltada para o leitor-criança, em especial, dos poetas José Paulo Paes e Manoel de Barros. Ambos os escritores expressam um projeto poético que testemunha a possibilidade de interferência do elemento poético no comportamento humano. São poetas que empregam a linguagem para que o leitor-criança (ou não) possa brincar com a língua e usufruir o prazer da imaginação. Assim, experimentar as possibilidades da língua (a fruição estética) leva o leitor a se tornar sujeito por obter a consciência de seu direito de uso da palavra. 


\section{LÚDICO E EXPEDIENTES LINGUÍSTICOS DE COMICIDADE}

Para a realização desta abordagem, adota-se a perspectiva teórica de Johan Huizinga que, em Homo Ludens, apresenta o jogo como elemento primordial da cultura e, especificamente, em capítulo intitulado "O Jogo e a Poesia", discute a relação existente entre jogo e poesia.

Ao comentar sobre a natureza da criação poética, Huizinga (1971) destaca que a poesia situa-se dentro da esfera lúdica do espírito, visto que transcende os limites do juízo lógico e da causalidade. Expressando-se por métodos distintos da lógica, a poesia cria um mundo próprio, o qual se posiciona num plano mais primitivo e originário, onde encontramos a criança, o animal, o selvagem e o visionário.

Notadamente, esse plano (mais primitivo e originário), para Huizinga (1971, p.133), configura-se na "região do sonho, do encantamento, do êxtase, do riso". Diante disso, o autor destaca que, se quisermos sentir a poesia, se faz necessário sermos crianças: isto é, devemos reconhecer e admitir a sabedoria infantil, como uma "capa mágica", superior à do adulto.

Dessa maneira, a criação poética aproxima-se da visão de mundo da criança. Paes e Barros reconhecem e sublinham essa necessidade. Esses poetas recorrem à linguagem da infância, 
além das cenas do cotidiano, para demonstrar a ousadia com as palavras. Como poetas-meninos, mediante o ponto de vista da criança, veem a poesia, do mesmo modo que Valéry (1991), como um jogo com as palavras e com a linguagem. Assim, possibilitam o cumprimento do papel da linguagem poética: "O que a linguagem poética faz é essencialmente jogar com as palavras" (HUIZINGA, 1971, p.149).

Paes e Barros articulam a poesia e o jogo. Criam poemas que transpõem a seriedade, fazendo da própria poesia um jogo. Para compreender isso, é fundamental que se considere a definição de jogo, dada por Huizinga, a qual é também estendida à poesia:

[O jogo é] uma atividade que se processa dentro de certos limites temporais e espaciais, segundo uma determinada ordem e um dado número de regras livremente aceitas, e fora da esfera da necessidade ou da utilidade material. 0 ambiente em que ele se desenrola é de arrebatamento e entusiasmo, e tornase sagrado ou festivo de acordo com a circunstância. A ação é acompanhada por um sentimento de exaltação e tensão, e seguida por um estado de alegria e de distensão. (HUIZINGA, 1971, p.147)

Vê-se que, de acordo com Huizinga, há o elemento lúdico na estrutura da imaginação criadora e a poesia está na região do riso. Por esse motivo, destaca-se a contribuição 
bergsonisiana para a conceituação de riso. No corpus, identifica-se a presença de três recursos linguísticos, apontados por Bergson (1983, p.64), a saber: a repetição, a inversão e a interferência.

Quanto à repetição, ocorre quando acontecimentos se repetem em novo tom ou em novo ambiente, ou quando são invertidos, conservando um sentido, ou quando se misturam de modo que suas significações interfiram entre si. No que se refere à inversão, surge quando, ao se ouvir uma frase, procura-se o sentido invertendo-a. A interferência, por sua vez, acontece quando dois sistemas de ideias interferem na mesma frase, dando-lhe duas significações independentes. Segundo Bergson (1983), há os seguintes meios de se obter a interferência: trocadilho (palavras diferentes, mas que se confundem por produzir o mesmo som); e jogo de palavras (diversidade de sentido que uma palavra pode assumir na passagem do sentido próprio ao figurado).

Outros expedientes observados em Paes e Barros são alogismo, trocadilho, paradoxo e ironia. Segundo Propp (1992, p.107), nas obras literárias, há homens dizendo coisas absurdas ou realizando ações insensatas: fatos que motivam o riso. Esse expediente (alogismo) pode ser entendido como um mecanismo de pensamento, em que 
o rumo dos raciocínios é inesperado e não há a capacidade de associar uma consequência às suas causas. O alogismo é semelhante àquilo que "na lógica das crianças é prova de suas primeiras e ingênuas indagações mentais, de suas tentativas de ligar um fenômeno com outro e de orientarse no mundo, na lógica dos adultos torna-se apenas um engano ridículo" (PROPP, 1992, p.110).

Ao abordar propriamente os instrumentos linguísticos da comicidade, Propp (1992) direciona sua atenção aos recursos encontrados na língua. Explica que esta não é cômica, porém reflete traços espirituais de quem fala. Diante disso, comenta sobre trocadilhos, paradoxos e algumas formas de ironia, os quais dependem em igual medida daquilo que exprimem.

Concernente ao trocadilho, chamado calembour em francês, parafraseando o dicionário da língua russa de S. I. Ójegar, Propp (1992, p.120) conceitua-o como "uma brincadeira baseada no emprego cômico de palavras semelhantes quanto ao som, mas diferentes quanto ao significado". A criação do calembour requer um talento particular e argúcia, visto que o sentido literal da palavra deve ser reconhecido e logo substituído pelo sentido mais amplo que está na mente do interlocutor. Vale ressaltar que esse recurso de comicidade, segundo Propp (1992, 
p.123), pode tanto se configurar em brincadeira inocente e bem-humorada, como também assumir um caráter ofensivo, caso seja dirigida contra os aspectos negativos da vida, por exemplo.

No que concerne ao paradoxo, Propp (1992, p.124) conceitua-o como sentença em que o predicado contradiz o sujeito. Já sobre a ironia, o autor revela que se expressa com palavras um conceito, mas se subtende outro exatamente contrário. Faz-se necessário destacar que, segundo Propp (1992), a comicidade do calembour, do paradoxo e da ironia depende tanto dos meios linguísticos quanto do conteúdo. Todavia, a estrutura fônica da língua usada provoca um desvio da atenção daquilo que é expresso para as formas exteriores de sua expressão.

Nesse sentido, Todorov (1980) lembra que a aproximação de palavras com sonoridades semelhantes, mas com sentidos diferentes tem valor cômico. Ademais, "o jogo de palavras avizinha-se do anormal: é a loucura das palavras" (TODOROV, 1980, p.289). Assim, a loucura acaba sendo uma das explicações possíveis para as práticas de jogos de palavras. A literatura, por sua vez, constrói-se a partir de sua afinidade com o jogo de palavras. 


\section{A POESIA PARA CRIANÇAS DE PAES E DE BARROS E O LÚDICO}

Segundo os pressupostos teóricos anteriormente citados, pode-se perceber que o lúdico permeia a linguagem poética, em especial, destinada ao público infantil dos poetas José Paulo Paes e de Manoel de Barros.

O livro Poemas para brincar foi publicado em 1990 e rendeu a José Paulo Paes o Prêmio Jabuti/91 de Melhor Livro Infantil e, ao ilustrador Luiz Maia, de Melhor llustração de Livro Infantil e Juvenil. É composto por 12 (doze) poemas, a saber: "Convite", "Cemitério", "Atenção, detetive", "Patacoada", "Pescaria", "Letra mágica", "Paraíso", "Gato da China", "Respostas", "Profissões", "Ana e o pernilongo" e "Dicionário".

Dezessete anos depois, o poeta Manoel de Barros publicou Poeminha em língua de brincar com ilustrações de Martha Barros. Diferentemente do livro de Paes que apresenta poemas independentes, Manoel de Barros oferece versos distribuídos em 13 páginas que oferecem uma narrativa sobre o menino e sua língua.

Ambos os livros não apresentam normas e conselhos morais ao leitor. No lugar de fins pedagógico-utilitários, há a ênfase no ato de brincar com a palavra e a evidência de que Paes e Barros elegem a poesia como tema de seus poemas. Por tornarem proeminente a metalinguagem, esses poetas 
instauram o diálogo com o receptor, a quem esclarecem suas concepções poéticas sempre marcadas pelo jogo e, como diria Huizinga (1971), assentadas na região do riso.

A partir da recriação da brincadeira por meio da língua, são recriados a alegria e o riso do mundo infantil. Nas páginas dos livros analisados, oferece-se um espaço em que se sobressaem a fantasia e a inventividade, possibilitando ao leitor a percepção de que não há limites à poesia e, por isso, as regras são dispensadas a favor da liberdade criadora.

Desse modo, Paes e Barros oferecem a prática da irreverência com a palavra poética. Além do que, tomam emprestadas muitas palavras pertencentes ao repertório e ao cotidiano da criança, fato que contribui para uma relação de proximidade com o universo infantil e provoca de imediato o interesse do leitor-mirim. Para exemplificar, transcreve-se o poema "Convite", de José Paulo Paes:

Convite

Poesia

é brincar com palavras

como se brinca

com bola, papagaio, pião.

Só que

bola, papagaio, pião

de tanto brincar

se gastam. 
As palavras não:

quanto mais se brinca

com elas

mais novas ficam.

Como a água do rio

que é água sempre nova.

Como cada dia

que é sempre um novo dia.

Vamos brincar de poesia?

(PAES, 2007)

Mediante a comparação entre as palavras e os brinquedos ("bola, papagaio, pião"), bem como entre as palavras e as imagens da "água do rio" e do "dia", Paes chama a atenção para uma das especificidades do discurso literário que é o caráter de novidade marcante no fazer poético e, como expõe o próprio título do poema, o sujeito lírico convida o leitor a brincar com as palavras, a brincar de poesia. Cabe salientar o desfecho do texto com frase interrogativa, visto que é uma estratégia que convoca a participação do leitor com quem o sujeito lírico pretende estabelecer cumplicidade. Em Poemas para brincar, há ainda outras frases interrogativas como, por exemplo, "e quem matou os piolhos/ da cabeça do alfinete?" que deixam aberta a possibilidade de respostas, um expediente promotor da suplementação do texto pelo leitor. 
No que se refere ao livro Poeminha em língua de brincar, apesar de não haver frases interrogativas, os versos convocam a cumplicidade do leitor ao promover o modo de pensar alógico - modo que, segundo Propp (1992, p.110), é bem particular à criança pois, na lógica infantil, surgem raciocínios inesperados e expressões absurdas devido à ingenuidade do infante, contrariando a lógica dos adultos e, até mesmo, motivando o riso. O livro de Barros inicia-se com as seguintes palavras: "Ele tinha no rosto um sonho de ave extraviada./ Falava em língua de ave e de criança". É interessante notar que a narrativa em versos barrianos conta sobre o "menino", personagem que, ao fazer suas brincadeiras com a língua, faz poesia e, consequentemente, faz-se poeta.

Se, por um lado, o menino (personagem que joga "pedrinhas no bom senso") se comporta como poeta, por outro lado, o poeta se comporta como menino. Por essas razões, Barros explora imagens formadas a partir de associações linguísticas inesperadas. A representação da criança nos versos se consolida pelas relações insólitas entre as palavras, ou seja, pela produção de um falar infantil. De fato, trata-se de uma maneira de renovar o uso da língua, pois impulsiona a surpresa e o estranhamento. 
O sujeito lírico barriano salienta a oposição entre pensar e brincar, bem como, na esteira de Mallarmé, salienta a oposição entre ideias e palavras para, então, ressaltar a preferência pela brincadeira: "Dispensava pensar". Barros volta a atenção para a língua de modo explícito, uma vez que são lidas as seguintes frases em Poeminha em língua de brincar: "Aprendera no Circo, há idos, que a palavra tem / que chegar ao grau de brinquedo/ Para ser séria de rir." O alógico é expresso por meio de paradoxo e, com o propósito de definir a língua de brincar, entra em cena uma "Dona de nome Lógica da Razão", personagem que expõe: "Isso é Língua de brincar e é idiotice de/ criança". Dessa forma, a língua de brincar é a língua da criança, que não se restringe à razão. Não cabe à poesia o utilitarismo, como já teorizou Perrotti (1986), isso justifica a construção paradoxal nestes versos de Barros (2007): “O menino sentenciou: /Se o Nada desaparecer a poesia acaba".

A reflexão metapoética é recorrente e sugerida, sobretudo, nos versos finais de Barros (2007): "E se internou na própria casca ao jeito que o/ jabuti se interna". Nessa imagem, sugere-se tanto a volta do sujeito para si mesmo, pensando sobre si próprio, quanto podem se referir à Dona Lógica da Razão que se opõe à língua de brincar e, por isso, 
comporta-se como o jabuti saindo de cena comicamente. Diante da plurissignificação do texto literário, resta ao leitor interpretar e cooperar com os sentidos, como teoriza Eco (2008).

Considerando os níveis de leitura de um poema, pode-se afirmar que Manoel de Barros enfatiza o nível sintático (a combinação surpreendente das palavras escolhidas). José Paulo Paes, por sua vez, explora principalmente o nível fonológico (as implicações da troca de fonemas e do som no significado).

Em especial, Paes emprega aliterações, assonâncias, anáforas, rimas como, por exemplo, nos poemas "Cemitério" e "Gato da China". Também destaca o sentido das palavras devido a uma única troca de fonemas como, por exemplo, no poema "Letra mágica"; salienta a polissemia dos homônimos pata (fêmea do pato) e pata (pé de animal), mencionados no poema "Patacoada".

Predominantemente, Barros traz o lúdico por meio de alogismos e paradoxos, já Paes joga com o significado das palavras por meio de trocadilhos e de inversão. Para Paiva (1961, p.300), “a inversão [...] é um processo frequente de lutar contra o peso morto e tradicional de certas construções, e de renovar a força expressiva dos vocábulos". Essa 
característica de Paes pode ser verificada, por exemplo, no poema "Dicionário" em que são oferecidos novos conceitos para certos vocábulos, proporcionando novas imagens das coisas sempre com comicidade. Desse poema, citam-se os excertos a seguir:

Aulas: período de interrupção das férias.

[...]

Sopapo: o que acontece

quando só

papo não adianta.

[...]

(PAES, 2007, grifos do autor)

José Paulo Paes, no poema "Respostas", provoca o riso ao complementar, com surpresa, os ditos populares como, por exemplo, “- Vá ver se eu estou na esquina./ - Fui e nada vi: o bobo estava aqui". Deve-se mencionar o resgate de catacreses em "Atenção, detetive", poema em que a imagem do detetive parece ser atribuída ao leitor-mirim, visto que a este cabe investigar sobre as possibilidades de uso da língua.

Como herdeiros do Modernismo, Paes e Barros indagamse sobre a forma de representação poética mediante a metapoesia e consideram a permanente liberdade (o inesperado e a surpresa) do processo de criação como algo necessário, por isso, recorrem ao jogo. Há a presença da lógica e da linguagem infantis e isso faz com que seus 
poemas exijam a atenção do leitor, que se vê diante de uma linguagem repleta de surpresas. O efeito de surpresa é um dos fatores de constituição da linguagem poética e significa a ocorrência de algo inesperado pelo leitor, mas que o conduz à aceitação de uma realidade nova.

A valorização da fantasia está presente em todo o livro Poemas para brincar, assim como em Poeminha em língua de brincar. Analogamente ao procedimento adotado por Barros quando ele alegoriza a palavra "Nada" com inicial maiúscula, no livro de Paes é frequente o uso de maiúsculas para chamar a atenção do leitor em poemas como "Ana e o pernilongo", de onde se extrai o seguinte trecho:

1

Toda semana

Eu me lembro da Ana

Para mim não semAna

Sem Ana.

[...] (PAES, 2007)

No que concerne às ilustrações, no livro de José Paulo Paes, elas se dão por meio de desenhos mais precisos, nos quais são reconhecidas com clareza figuras como bola, pião, pato, etc. Por outro lado, as ilustrações no livro de Barros ensaiam desenhos e riscos infantis e/ou primitivos, sendo desenhos plurissignificativos que podem ser livremente interpretados pela criança. Todavia, tanto em Paes quanto em Barros, as ilustrações esperam pela interação com o 
leitor, visto que complementam o universo lúdico explorado pelos poetas.

Poemas para brincar e Poeminha em língua de brincar demonstram um modo lúdico de apresentar poesia às crianças. Em ambos os livros, há sinestesias que convidam a sensibilidade do leitor a sentir as imagens construídas com a palavra, como diria Paz (1982). Destacam os valores poéticos obtidos mediante a exploração dos recursos da língua e o leitor-criança é levado a entender a poesia como mais um de seus brinquedos.

\section{CONSIDERAÇÕES FINAIS}

Os livros de Paes e de Barros, aqui analisados, levam o leitor-criança a pensar sobre o sentido das palavras e a desenvolver a competência linguística, isto é, a habilidade do uso da palavra. Seus poemas permitem à criança o despertar da fantasia e o exercício da reflexão sobre o que é poesia, no qual o fazer poético é entendido como a possibilidade de brincar com as palavras.

O lúdico na poesia traduz a atividade criadora que possibilita ao poeta (e ao homem) o desfrute da liberdade espiritual, a exposição da potencialidade imaginativa; deixa de lado o interesse material, delimita as suas próprias regras e sua própria ordem. Ao analisar os poemas de Paes 
e Barros, vê-se que o inesperado e a surpresa emergem dos jogos verbais, nos quais o brincar é evocado pelo fato de oferecer uma estreita relação entre a atitude infantil e a atitude do poeta.

Paes e Barros assumem o olhar da criança. Ao menino e ao poeta, todas as coisas são possíveis graças ao jogo. Não há princípios moralizantes; há, sim, a poesia com seu estatuto artístico, apresentando-se como entretenimento e fonte de criatividade. Assim, a discussão sobre o fazer poético por meio do lúdico é apresentada ao leitor-criança, a fim de que este compreenda a importância da literatura desde cedo e desenvolva o gosto pela leitura.

Não é possível falar de literatura infantil e não relacionála à escola, instituição oficialmente responsável pela formação do indivíduo para a vida por meio da leitura. Por isso, Magnani (1989) enfatiza a necessidade da prática da leitura de textos literários em sala de aula. Segundo a autora, cabe ao professor inserir a literatura em sala de aula e, para tanto, este profissional deve ler bons materiais para ensinar o gosto de ler aos seus alunos. Conforme Zilberman (1991), o acesso ao texto literário é uma maneira de estimular a leitura e o gosto de ler, os quais favorecem o fortalecimento da arte literária. 
A literatura infantil é emancipatória, uma vez que proporciona o exercício da imaginação, o desenvolvimento do pensamento crítico e da capacidade de solucionar problemas com criatividade, explica Cademartori (1987, p.19). Por essas razões, espera-se divulgar os trabalhos poéticos de Paes e Barros voltados para as crianças, com o fito de que seus poemas frequentem mais as salas de aula e que, como Cagliari (1997) expõe, as crianças tenham contato com bons autores.

\section{REFERÊNCIAS:}

Barros, Manoel de Barros (2007). Poeminha em língua de brincar. Rio de Janeiro: Record.

Cademartori, Ligia (1987). O que é Literatura Infantil (4a ed.). São Paulo: Brasiliense.

Cagliari, Luiz Carlos (1997). Alfabetização \& Linguística. São Paulo: Scipione.

Eco, Umberto (2008). Os limites da interpretação. Tradução Pérola de Carvalho (2a ed.). São Paulo: Perspectiva.

Huizinga, Johan (1971). Homo Ludens - O jogo como elemento da cultura. (João Paulo Monteiro Trad.). São Paulo: Perspectiva/ USP.

Magnani, Maria do Rosário M. (1989). Leitura, Literatura e Escola - Sobre a formação do gosto. São Paulo: Martins Fontes.

Paes, José Paulo (2007). Poemas para brincar (16a ed.). São Paulo: Ática. Paiva, Maria Helena de. (1961). Contribuição para uma estilística da ironia. Lisboa: Centro de Estudos Filológicos.

Paz, Octavio (1982). O arco e a lira. Tradução Olga Savary. Rio de Janeiro: Nova Fronteira. 
Perrotti, Edmir (1986). O texto sedutor na literatura infantil. São Paulo: Ícone. Propp, Wladimir (1992). Comicidade e riso. Tradução Aurora F. Bernardini e Homero F. de Andrade. São Paulo: Ática.

Todorov, Tzvetan (1980). Os gêneros do discurso. (Elisa A. Kossovitch, Trad.). São Paulo: Martins Fontes.

Turchi, Maria Zaíra \& SILVA, Vera Maria Tietzmann (Orgs.) (2002). Literatura infanto-juvenil: leituras críticas. Goiânia: Editora da UFG.

Valéry, Paul (1991). Variedades. Tradução Maiza Martins de Siqueira. São Paulo: lluminuras.

Zilberman, Regina (1991). A leitura e o ensino de literatura (2a ed.). São Paulo: Contexto.

.(2005). Como e por que ler a literatura infantil brasileira. Rio de Janeiro: Objetiva.

.\& Magalhães, Ligia Cademartori (1987). Literatura infantil: autoritarismo e emancipação. São Paulo: Ática.

Nismária Alves David é Professora de Literatura (UEG/ Pires do Rio). PósDoutoranda do PACC/UFRJ. Doutora em Letras e Linguística (UFG, 2010). Mestre em Estudos Literários (UNESP, 2004). nisdavid@yahoo.com.br 